pronuclear fusion occurs in mammals. It might also be noted that the data surveyed by Van Teinhoven takes us up to 1980-81 and clearly in the most rapidly developing areas, such as testicular physiology, some of the concepts presented may be dated or incomplete.

The book does not, however, set out to cope with the sort of ephemerae found in symposium volumes. It is intended to be an introduction through which students and researchers entering the field of reproduction might gain a perspective on this process as it occurs in vertebrates; in this respect, it admirably succeeds.

R. J. Aitken is in the MRC Reproductive Biology Unit, Edinburgh.

\section{Getting around}

\section{J.R.S. Fincham}

\section{Mobile Genetic Elements.}

Edited by James A. Shapiro.

Academic: 1983. Pp.688. £43, \$65.

DURING the past decade the orderly world of cytogenetics has been increasingly disturbed by the intrusion of a miscellaneous and apparently unruly collection of mobile genetic elements. Their influence has grown to the point where knowledge of their prevalence and properties is essential to anyone wishing to keep abreast of current thinking about such important topics as spontaneous mutation, genome evolution and oncogenesis. The time was certainly ripe for an authoritative account of movable sequences, and James Shapiro has organized one. He could hardly have assembled a better team of authors. All are in the forefront of research in their respective areas and all write well, with a real attempt to make their chapters mutually relevant.

Approximately equal weight is given to prokaryotic and eukaryotic systems. Four chapters are concerned with freely roaming prokaryotic sequences: Iida, Meyer and Arber deal with bacterial insertion sequences (IS), Heffron with transposon $3(\operatorname{Tn} 3)$, Kleckner with Tn10 and Toussaint and Resibois with the bacteriophage $\mathrm{Mu}$, for which transposition is a way of life. Sitespecific integration and excision is described by $\mathrm{A}$. Campbell, using the example of bacteriophage lambda, for the elucidation of which he was himself largely responsible. Controlled segmental inversion as a means of reversible differentiation in bacterial and bacteriophages is represented by phase variation in Salmonella typhimurium in the chapter by Simon and Silverman. The Salmonella inversionswitch also appears in the context of Tn3, with which it appears to share a common mechanism and, presumably, a common origin. This example serves to emphasize the likelihood that "selfish" DNA sequences will sometimes be "recruited" to provide useful functions in the regular genome.

Among the chapters dealing with eukaryotic systems, that by Varmus on retroviruses is of central importance. He stresses the extraordinary sequence similarities seen between parts of retrovirus genomes, several kinds of roaming Drosophila elements (reviewed by Rubin) and the Tyl element of yeast (described by Roeder and Fink). The suspicion grows that many of the dispersed, repetitive and occasionally movable sequences that bulk so largely in higher eukaryote genomes may be spread by retrovirus-like reverse transcription.

Bregliano and Kidwell provide an integrated account of the different agents of hybrid dysgenesis in Drosophila melanogaster. The molecular affinities of these elements have yet to be determined, but their properties show a striking resemblance in several respects to those of the maize transposable elements described in the 1950 s by Barbara McClintock and reviewed here by Nina Fedoroff. There are further chapters (by Schell et al., Haber and Borst respectively) on the Agrobacterium-Ti plasmid-plant system (essential

\section{Petal pursuits}

\section{Peter D. Moore}

Double Flowers: A Scientific Study.

By Joan Reynolds and John Tampion.

Pembridge Press, 16 Pembridge Road,

London WII 3HZ: 1983. Pp.183. £9.75.

SO WEL.L established is the historic divergence of horticulturists and academic botanists that many of the processes which the former take for granted are casually neglected by the latter. Among such is the phenomenon of double flowers. Even the term leaves much to be desired, for it includes a range of floral modifications such as petal proliferation, dissection and the adoption of petaloid form by other floral organs. The authors of Double Flowers have attempted to bring together the scattered fragments of information about this subject in the literature, which commences with the observations of Theophrastus in the third century $\mathrm{BC}$. They also seek to classify double flowers on morphogenetic criteria and to examine their physiological and genetic basis.

One of the main causes of the average plant scientist's suspicion of things horticultural undoubtedly stems from the use in the latter of English variety names which provide little information concerning parentage. The authors here do nothing to ease such doubt in their use of English names even for wild plants in which doubleness has been observed. There is a pervading scent of imprecision here.

What could have been the most valuable reading for would-be plant genetic engineers), and on the yeast mating-type and trypanosome surface glycoprotein switch mechanisms. The last two topics, like vertebrate immunoglobulin gene switching (not included here) perhaps really belong in a different book, but it is good to have them so well reviewed.

The editor, in his introduction, remarks that "these thoughtful reviews will not quickly become dated", and I agree with him. At the same time, they will quickly become supplemented by new information. Several of the systems described, notably the maize elements and the Drosophila hybrid dysgenesis elements, have only recently been cloned and are now being sequenced. In a few years' time we shall know much more, and it may be possible to propose a rational taxonomy of movable elements based on structure, transposition mechanism and presumed evolutionary relationships. This book is to be heartily welcomed, but we shall soon need another one. I hope that Dr Shapiro will undertake it.

J.R.S. Fincham is Buchanan Professor of Genetics at the University of Edinburgh.

chapters in the book are those which review morphogenetic and physiological research in this area. The literature covered is very full and, undoubtedly, the bibliography will prove valuable, but the chapters suffer from the problem that the authors assume that the reader will already be aware of previous work. For example, "The work of X (1957) and Y (1975) is still, of course, interesting". This is hardly likely to inform the uninitiated.

Perhaps this style is explained by the fact that the book has developed out of a doctoral thesis. This becomes even more evident in the second part of the work, when five case studies of doubleness are considered. Four of these are reported in great detail and have clearly been the objects of the authors' own research. The wealth of practical detail and the tabulated results, together with the well-produced photomicrographs, contrast strongly with the earlier chapters.

Double Flowers has succeeded in two respects. It has set up a classificatory scheme for "doubleness" based in part upon the original floral structure (polypetalous, sympetalous, etc.) and in part upon the morphogenetic origin of the aberration. It has also provided some detailed analyses of a range of such floral types. What the authors have not succeeded in doing is presenting the subject adequately to those on the fringes (physiologists, morphologists, geneticists, taxonomists, etc.). But perhaps this is asking too much of a study which is evidently still in its infancy.

Peter D. Moore is Senior Lecturer in the Department of Plant Sciences, King's College, University of London. 